\title{
Ophthalmology training in sub-Saharan Africa: a scoping review
}

\author{
William H. Dean $\mathbb{1}^{1,2} \cdot$ John C. Buchan $\mathbb{1}^{1,3} \cdot$ Stephen Gichuhi $\mathbb{1}^{4} \cdot$ Hannah Faal ${ }^{5} \cdot$ Caleb Mpyet $^{6} \cdot$ \\ Serge Resnikoff $\mathbb{1}^{7} \cdot$ Iris Gordon $^{1} \cdot$ Ibrahim Matende $^{8,9} \cdot$ Andrew Samuel $^{10} \cdot$ Linda Visser $^{11} \cdot$ Matthew J. Burton ${ }^{1,12}$
}

Received: 4 May 2020 / Revised: 12 November 2020 / Accepted: 18 November 2020 / Published online: 15 December 2020

(c) The Author(s), under exclusive licence to The Royal College of Ophthalmologists 2020

\begin{abstract}
Sub-Saharan Africa is home to $12 \%$ of the global population, and 4.3 million are blind and over 15 million are visually impaired. There are only 2.5 ophthalmologists per million people in SSA. Training of ophthalmologists is critical. We designed a systematic literature review protocol, searched MEDLINE Ovid and Embase OVID on 1 August 2019 and limited these searches to the year 2000 onwards. We also searched Google Scholar and websites of ophthalmic institutions for additional information. We include a total of 49 references in this review and used a narrative approach to synthesise the results. There are 56 training institutions for ophthalmologists in eleven Anglophone, eleven Francophone, and two Lusophone SSA countries. The median duration of ophthalmology training programmes was 4 years. Most curricula have been regionally standardised. National, regional and international collaborations are a key feature to ophthalmology training in more than half of ophthalmology training programmes. There is a drive, although perhaps not always evidence-based, for sub-specialisation in the region. Available published scientific data on ophthalmic medical and surgical training in SSA is sparse, especially for Francophone and Lusophone countries. However, through a broad scoping review strategy it has been possible to obtain a valuable and detailed view of ophthalmology training in SSA. Training of ophthalmologists is a complex and multi-faceted task. There are challenges in appropriate selection, capacity, and funding of available training institutions. Numerous learning outcomes demand curriculum, time, faculty, support, and appropriate assessment. There are opportunities provided by modern training approaches. Partnership is key.
\end{abstract}

\section{Introduction}

The 49 countries of sub-Saharan Africa (SSA) are home to $12 \%$ of the global population, one billion people [1]. Over 4 million of the population are blind (presenting visual acuity <3/60) [2, 3]. The age-standardised prevalence of blindness is $0.97 \%$, and $41 \%$ of blindness is due to cataract [4]. Other leading causes of blindness include: uncorrected refractive error $12.5 \%$, glaucoma $12.5 \%$,

William H. Dean

will.dean@1shtm.ac.uk

1 International Centre for Eye Health, London School of Hygiene and Topical Medicine, London, UK

2 University of Cape Town, Cape Town, South Africa

3 Leeds University Teaching Hospitals NHS Trust, Leeds, UK

4 Department of Ophthalmology, University of Nairobi, Nairobi, Kenya

5 University of Calabar and Teaching Hospital, Calabar, Nigeria macular degeneration $4.5 \%$, trachoma $4.3 \%$, and diabetic retinopathy $0.5 \%[5]$.

Of the more than 230,000 ophthalmologists worldwide, there are only 2.5 ophthalmologists per million population in SSA, against a global mean of 31.7 [6]. Training of all cadres of eye health workers, including ophthalmologists, is crucial if the goals of VISION 2020 are to be attained, and universal eye care achieved [7]. We need to look beyond 2020 with an aim to achieving Sustainable
6 Department of Ophthalmology, University of Jos, Jos, Nigeria

7 International Health \& Development, Geneva, Switzerland

Lighthouse for Christ Eye Centre, Mombasa, Kenya

9 College of Ophthalmology of Eastern, Central and Southern Africa, Nairobi, Kenya

10 University of Manitoba, Winnipeg, MB, Canada

11 Department of Ophthalmology, University of KwaZulu-Natal, Durban, South Africa

12 Moorfield's Eye Hospital, London, UK 
Development Goal 3: Good Health and Well-being. In a sample of 21 countries in SSA in 2011, only five (Botswana, The Gambia, Kenya, Senegal and Sudan) met the VISION 2020 target ratio of eye surgeons per million population. VISION 2020 recommended a target of four ophthalmologists per million population, however most $(80 \%)$ of the sample SSA countries had fewer than this. Of these, nearly $70 \%$ work in their respective capital city $[8,9]$.

There are 56 training institutions for ophthalmologists in 11 Anglophone, 11 Francophone, two Lusophone countries (Table 1) [10]. Setting up training institutions is challenging in situations with huge needs for clinical service provision; they are limited by available teaching faculty, time, financial and other resource constraints. Furthermore, the demand for services is often far less than the population need, with relatively low numbers of patients affording and seeking care. At the advent of VISION 2020 in 1999, initial priority actions within SSA included the 'development of collaborative regional training programmes for ophthalmologists to improve the quality of education and to increase the number of trainees' [11].

We therefore conducted a scoping literature review looking at peer-reviewed published papers and open-access resources from associated training colleges, governmental and non-governmental organisations.

\section{Methods}

We searched MEDLINE Ovid and Embase OVID on 1 August 2019 and limited these searches to the year 2000 onwards. Searches were created using terms for ophthalmic staff and training. We used a search filter developed by the library services at the London School of Hygiene and Tropical Medicine to limit the results to reports pertaining to SSA. We did not impose any language limits on the search. The search strategies are available as an online appendix to this article. We checked the reference lists for potentially relevant studies and identified a further 17 references that met our inclusion criteria. Two authors independently reviewed full text articles and extracted the data independently.

We made a concerted effort to access as much grey literature as possible to ensure that relevant information not included in published literature could be included in this review. We undertook searches of Google Scholar and various eye related websites to identify entities who may have information on the provision of ophthalmology training. French terms included 'formation en ophtalmologie'; and Portuguese 'treinamento em oftalmologia'.

Data were specifically searched and collected under broad categories:
- Strategy, oversight and regulation.

- Selection, entry requirements and demographics.

- Ophthalmology training programme: duration, curricula, assessments, resources and support, funding, faculty, surgical education, and continuing medical education (CME).

- Fellowship or sub-speciality ophthalmology training.

- Exit examinations, qualifications, certification (local, national, regional and international).

- External input from Links, Non-Government Organisations, and visiting faculty.

- Broader training as part of the eye care team, research, and leadership.

\section{Results}

The search yielded a total of 548 references. After 182 duplicate records were removed, we screened the remaining 366 references and identified 32 references which met the inclusion criteria. After checking the reference lists of these articles, we identified a further 17 articles which were eligible for inclusion in the review. In total, we included 49 referenced articles in this review (Table 2).

In total, we identified 56 training institutions (Table 1), six ophthalmology colleges in SSA (Table 3), 32 ophthalmological societies (Table 4), and 25 NGOs (Table 5). International agencies and organisations who are involved with ophthalmology training and education in Africa were also included in the search (Table 6). A total of 61 websites and publicly available reports were included in the grey literature review. Figure 1 summarises the search methodology and results. Most evidence was at the level of expert opinion and surveys (which accounted for $90 \%$ of papers). There were no meta-analyses or systematic reviews.

\section{Strategy and targets, oversight, regulation and accreditation}

At a national and sub-national level, targets for human resources for eye health $(\mathrm{HReH})$ are useful for planning, monitoring, and resource mobilisation, but they need to be updated and informed by evidence of effectiveness and efficiency [7].

Surgical training programmes in much of the West Africa sub-region are accredited through periodic audits of manpower, facilities, clinical services and academic programmes [12]. Ophthalmology training in Nigeria is further regulated and accredited by the National Postgraduate Medical College of Nigeria and the Medical and Dental Council of Nigeria, and in Ghana by the Ghana College of Physicians and Surgeons. The College of Ophthalmology within the Colleges of Medicine South Africa has oversight 
Table 1 Ophthalmology Training Institutions SSA [10].

\begin{tabular}{|c|c|c|c|c|c|}
\hline Country & Institution & Duration (years) & Degree & Number of faculty & Yearly capacity \\
\hline Angola & IONA Eye Institute, Luanda & 4 & Ophthalmology specialist & 4 & 4 \\
\hline Benin & University of Abomey, Calavi & & Diplôme d'Etudes Spécialisées (DES) ${ }^{\mathrm{a}}$ & & 8 \\
\hline Burkina Faso & National University Hospital Yalgado Ouédraogo, Ouagadougou & & DES & & 3 \\
\hline Cameroon & Magrabi ICO Cameroon Eye Institute & & Fellowship & & \\
\hline Cameroon & Faculty of Medicine and Biomedical Sciences, University of Yaoundé & & DES & & 8 \\
\hline Cote d'Ivoire & University of Cocody & & DES & & 6 \\
\hline Congo, DR & University of Kinshasa & & DES & & 5 \\
\hline Congo, DR & University of Lubumbashi & & DES & & 5 \\
\hline Ghana & Korle Bu Teaching Hospital, Accra & 4 & Fellowship & & 5 \\
\hline Ghana & Komfo Anoky Teaching Hospital, Kumasi, Ashanti & 3 & Membership & & 3 \\
\hline Guinea & Donka University Teaching Hospital, Conakry & & Diploma & & 10 \\
\hline Ethiopia & Addis Ababa University, Medical Faculty, Dept. of Ophthalmology & 4 & Speciality certificate & 11 & 7 \\
\hline Ethiopia & Jimma University & 4 & Speciality certificate & 6 & 6 \\
\hline Ethiopia & University of Gondar & 4 & Speciality certificate & 7 & 6 \\
\hline Kenya & $\begin{array}{l}\text { University of Nairobi (UON), College of Health Sciences, School of } \\
\text { Medicine }\end{array}$ & 3 & MMed (Ophth) & $20^{\mathrm{c}}$ & 12 \\
\hline Madagascar $^{\mathrm{b}}$ & Faculty of Medicine, Antananarivo & 4 & DES & 4 & 10 \\
\hline Malawi & College of Medicine, University of Malawi, Blantyre & 4 & MMed & 4 & 2 \\
\hline Mali & IOTA, Bamako & & DES & & 10 \\
\hline Mozambique & Maputo Central Hospital & 4 & Ophthalmology specialist & 5 & 4 \\
\hline Niger & Niamey National Hospital & & DES & & 5 \\
\hline Nigeria & University College Hospital, Ibadan & 5 & Fellowship & 14 & 6 \\
\hline Nigeria & $\begin{array}{l}\text { Ahmadu Bello University Teaching Hospital, Shika, Zaria, } \\
\text { Kaduna State }\end{array}$ & 5 & Fellowship & 7 & 5 \\
\hline Nigeria & Lagos University Teaching Hospital, Idi- Araba & 5 & Fellowship & 7 & 5 \\
\hline Nigeria & Lagos State University Teaching Hospital, Ike & 5 & Fellowship & 6 & 5 \\
\hline Nigeria & Eye Foundation Hospital, Ikeja & 5 & Fellowship & 13 & 6 \\
\hline Nigeria & Olabisi Onabanjo University Teaching Hospital, Sagamu & 5 & Fellowship & 4 & 2 \\
\hline Nigeria & Obafemi Awolowo University Teaching Hospital & 5 & Fellowship & 6 & 5 \\
\hline Nigeria & University of Benin Teaching Hospital, Benin City & 5 & Fellowship & 14 & 5 \\
\hline Nigeria & University of Calabar Teaching Hospital, Calabar & 5 & Fellowship & 5 & 4 \\
\hline Nigeria & University of Port-Harcourt Teaching Hospital, Port-Harcourt & 5 & Fellowship & 9 & 3 \\
\hline Nigeria & Guiness Eye Centre, Nnamdi Azikiwe University, Onitsha & 5 & Fellowship & 8 & 4 \\
\hline Nigeria & University of Nigeria Teaching Hospital, Enugu & 5 & Fellowship & 16 & 8 \\
\hline Nigeria & University of Ilorin Teaching Hospital, Ilorin & 5 & Fellowship & 8 & 5 \\
\hline Nigeria & Jos University Teaching Hospital, Jos & 5 & Fellowship & 6 & 4 \\
\hline Nigeria & National Eye Centre, Kaduna & 5 & Fellowship & 14 & 6 \\
\hline Nigeria & Aminu Kano University Teaching Hospital, Kano & 5 & Fellowship & 10 & 4 \\
\hline Nigeria & $\begin{array}{l}\text { St.Mary Catholic Eye Hospital/Eleta Eye Institute/Atapa Eye } \\
\text { Care Iseyin }\end{array}$ & 5 & Fellowship & 6 & 4 \\
\hline Senegal & University Cheickh Anta Diop, Dakar & & DES & & 4 \\
\hline Rwanda & Rwanda International Institute of Ophthalmology, Kigali & 4 & MMed (Ophth) & 3 & 4 \\
\hline South Africa & Stellenbosch University & 4 & MMed and FCOphth & 6 & 2 \\
\hline South Africa & University of the Free State, Bloemfontein & 4.5 & MMed and FCOphth & 2 & 8 \\
\hline South Africa & University of Cape Town & 4 & MMed and FCOphth & 17 & 3 \\
\hline South Africa & University of KwaZulu-Natal, Durban & 4 & MMed and FCOphth & 13 & 3 \\
\hline South Africa & Sefako Makgatho Health Sciences University & 4 & MMed and FCOphth & 5 & 2 \\
\hline South Africa & University of Pretoria & 4 & MMed and FCOphth & 5 & 2 \\
\hline South Africa & Walter Sisulu University Umtata & 4 & MMed and FCOphth & 4 & 6 \\
\hline South Africa & Wits University Johannesburg & 4 & MMed and FCOphth & 16 & 4 \\
\hline Tanzania & Kilimanjaro Christian Medical University College, Arusha & 4 & MMed (Ophth) & 9 & 10 \\
\hline Tanzania & Muhimbili University of Health and Allied Sciences, Dar es Salaam & 4 & MMed (Ophth) & 6 & 5 \\
\hline Togo & Faculty of Medicine and Pharmacy, University of Lome & & DES & & 5 \\
\hline Uganda & Makerere University, College of Health Sciences, Kampala & 3 & MMed (Ophth) & 4 & 8 \\
\hline Uganda & Mbarara University of Science and Technology & 3 & MMed (Ophth) & 6 & 8 \\
\hline Zambia & University of Zambia School of Medicine Lusaka & 4 & MMed (Ophth) & 4 & 4 \\
\hline Zimbabwe & University of Zimbabwe, Dept. of Ophthalmology, Harare & 4 & Masters in Medicine & 5 & 6 \\
\hline Zimbabwe & United Bulawayo Hospitals & 4 & MMEd and FCOphth & 2 & 3 \\
\hline
\end{tabular}

${ }^{a}$ Many Francophone countries deliver Diplôme d'Etudes Spécialisées (DES), which allows graduates to practice ophthalmology as a specialised MD. This could be translated as degree or diploma.

'Madagascar also provides 2-year training in 'essential ocular surgery' to MDs who then are allowed to practice cataract surgery. This training is additional and different from the 4 years training leading to a DES.

${ }^{\mathrm{c}}$ Academic faculty are 12 and the rest are $\mathrm{KNH}$ teaching hospital consultants who also augment the UON—an example of partnership. 


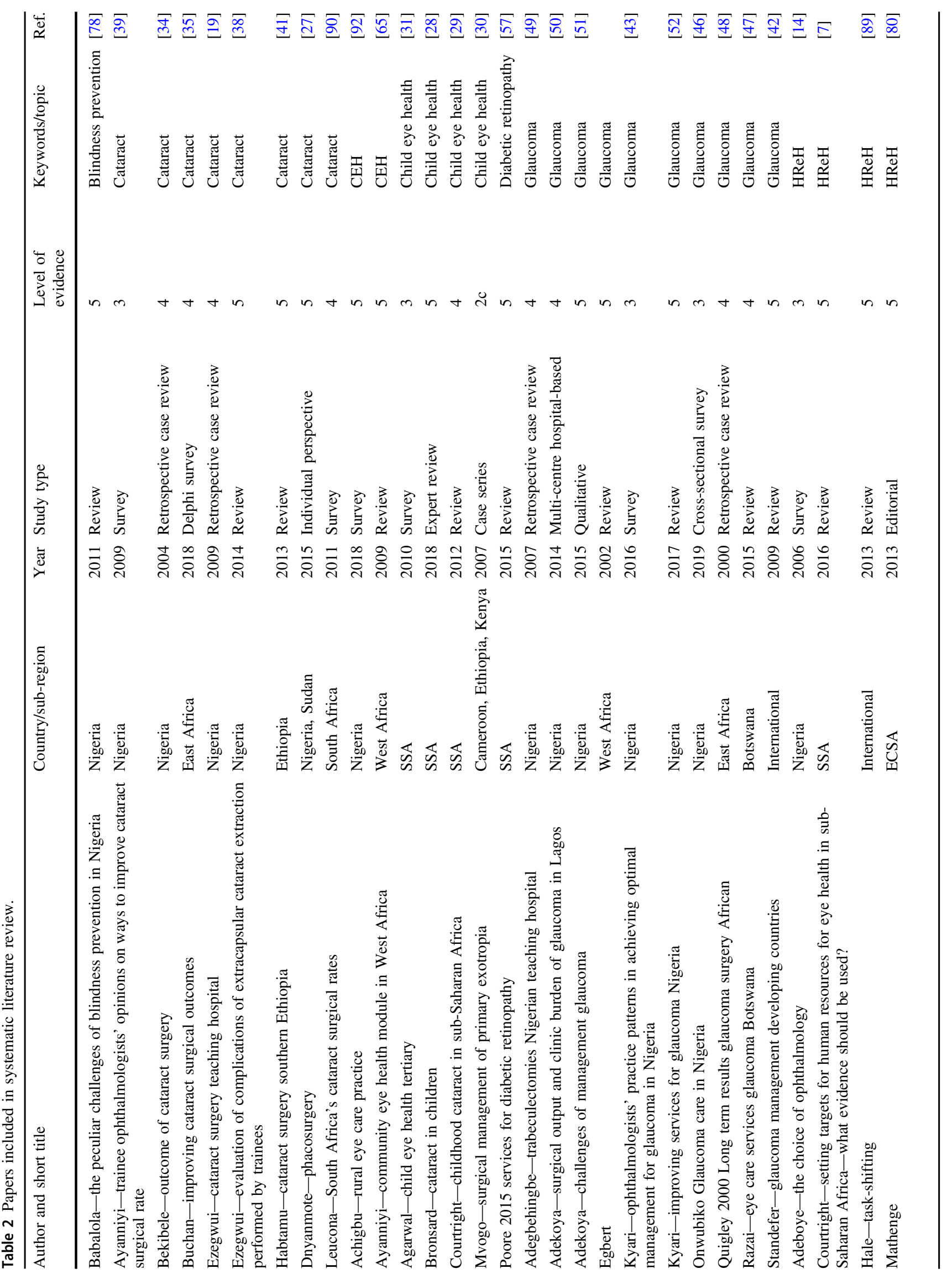




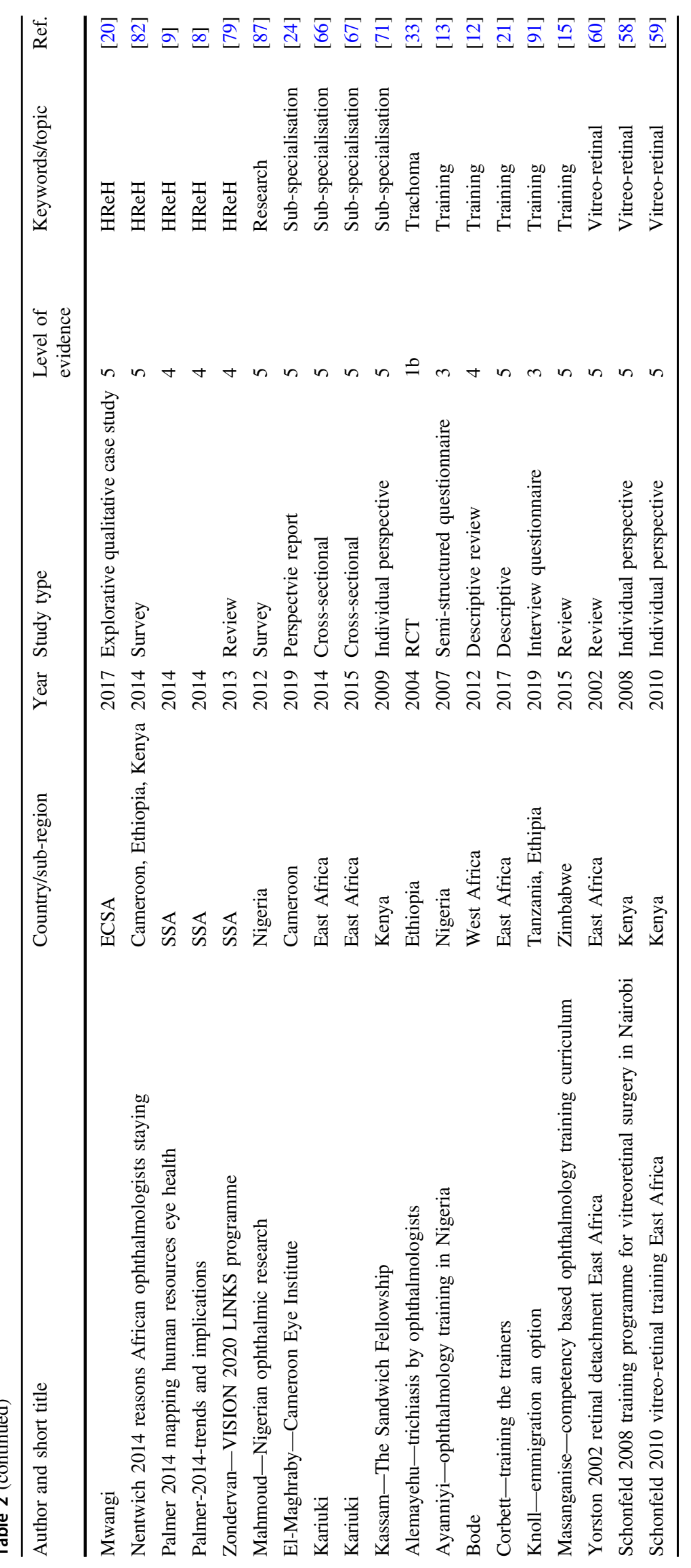


Table 3 The six regional ophthalmology colleges in SSA.

College of Medicine South Africa-College of Ophthalmology

College of Ophthalmologists of Eastern, Central and Southern Africa

Faculty of Ophthalmology, Ghana College of Physicians and Surgeons

Faculty of Ophthalmology, National Postgraduate Medical College of Nigeria

Mozambique College of Ophthalmology

West African College of Surgeons-Faculty of Ophthalmology https://www.cmsa.co.za/view_college.aspx?collegeid=13

http://www.coecsa.org

https://gcps.edu.gh/?page_id=2385

http://npmcn.edu.ng/faculties/faculty-of-ophthalmology/

http://ordemdosmedicos.org.mz

http://www.wacscoac.org/index.php/faculties/ophthalmology

CAMES (Conseil Africain et Malgache pour l'Enseignement Supérieur) is not a college, but plays the leading role in coordinating post graduate national trainings and delivering professorships [https://www.lecames.org/].

Table 4 Ophthalmological societies in SSA.

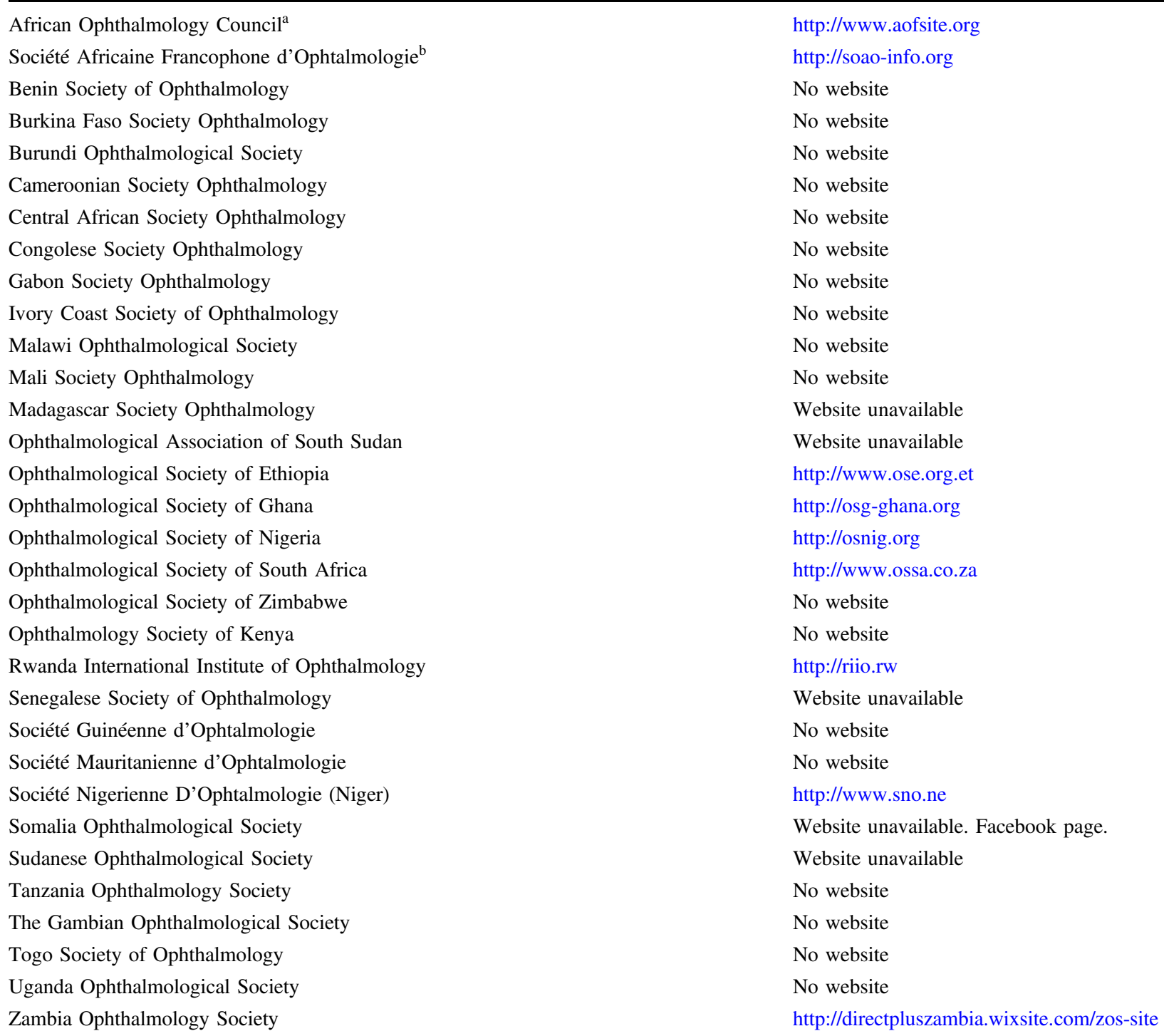

${ }^{a}$ The AOC is a supra-national ophthalmology organisation, representing interests of national and sub-regional ophthalmological societies across SSA.

${ }^{\mathrm{b}} \mathrm{SAFO}$ is a supranational professional society (federation of national societies also accepting individual membership, especially for ophthalmologists from Francophone countries where there is no national society). 
Table 5 Non-government organisations.

\begin{tabular}{ll}
\hline Brien Holden Vision Institute & www.brienholdenvision.org/ \\
CBM & www.cbm.org/ \\
Commonwealth Eye Health Consortium & http://cehc.lshtm.ac.uk \\
Cure Blindness & http://www.cureblindness.org \\
Fred Hollows & www.hollows.org/ \\
Fondation Sanofi-Espoir & http://fondation-sanofi-espoir.com/en/ \\
Helen Keller Foundation & www.helenkellerfoundation.org \\
IAPB & www.vision2020.org \\
International Eye Foundation & www.iefusa.org/ \\
KCCO & www.kcco.net/ \\
Light for the World & www.light-for-the-world.org \\
Lighthouse & www.lighthouse.org/ \\
Lions Clubs & www.lionsclubs.org \\
Ophthalmo Sans Frontieres & www.opht-sans-frontieres.org \\
ORBIS & www.orbis.org/ \\
Organisation for the Prevention of & www.opc.asso.fr/ \\
Blindness & \\
Rothschild Foundation & www.fo-rothschild.fr \\
SEE & www.seeintl.org/ \\
Seva Foundation & www.seva.org/ \\
Sight for All & sightforall.org/ \\
SightLife & www.sightlife.org \\
SightSavers & www.sightsavers.org \\
Thea Foundation & www.laboratoires-thea.com/en/fonda \\
Unite for Sight & www.uniteforsight.org \\
Vision Mundi & http://www.visionmundi.org \\
\hline & \\
&
\end{tabular}

Inclusion criteria were non-government or charity organisation, working in one or more countries in SSA, working in eye care or blindness prevention. The list was updated with input from co-authors, and when extracting data from referenced articles and websites searched. Websites were searched for terms 'education', 'training', 'surgery', 'curriculum', 'ophthalmology'.

Table 6 International agencies and organisations.

French Academy of Ophthalmology (AFO)

French College of Ophthalmology (COUF)

French Society of Ophthalmology (SFO) https://www.sfo.asso.fr

International Agency for the Prevention of www.iapb.org

Blindness-Africa

International Centre for Eye Health http://iceh.lshtm.ac.uk

International Council of Ophthalmology www.icoph.org

for training ophthalmologists and examination standard setting (Table 2).

\section{Selection, entry requirements and demographics}

Senegal required trainees to be a state medical doctor hospital intern. The two training programmes in Ghana, one in Zimbabwe, and four in South Africa stipulated registration with the National Medical \& Dental Council, or Health Professional Council as entry requirement. One university in South Africa required applicants to have passed the first part of the College of Ophthalmologists exam. Other training programmes $(41 / 51 ; 80.4 \%)$ required only a medical degree (MD, MBBS, or MBChB) [10]. There is variation of the age range of trainees. A survey in Nigeria reported trainees' age range of 29-51 with a mean of 34.7 years [13].

In Nigeria, $6.6 \%$ of medical interns reported they would chose ophthalmology as a first choice for career [14]. There is a reported lack of formal ophthalmology training curricula for medical graduates, with associated ad hoc training of undergraduates in ophthalmology, and inconsistent assessment [15].

\section{Ophthalmology training programme: duration, curricula, assessments, resources and support, funding, faculty, surgical education, and contining medical education (CME)}

For the 56 training institutions for ophthalmologists in eleven Anglophone, eleven Francophone, and two Lusophone SSA countries (Table 1), there was a total combined annual training intake capacity of 287 [10]. The median duration of ophthalmology training programmes was 4 years (mean 4.2 years) with a range from 3 years (most programmes in East Africa) to 5 years (all of the 18 training programmes in Nigeria). Sixteen (31.4\%) trainees in a Nigerian survey had stayed between 6 and 10 years in the programme [13].

In general, residency training is funded by individuals, national Ministries of Health, and non-government organisation (NGO) [16]. Tables 4, 7 illustrate NGOs with specific reference to those supporting ophthalmology training.

The International Agency for the Prevention of Blindness (IAPB) and the African Ophthalmology Council (AOC), together with presidents of the six colleges of ophthalmology in SSA and the Société Africaine Francophone d'Ophtalmologie (SAFO) met in Ghana in early 2016. The aim of this historic meeting was to explore harmonising a curriculum for ophthalmology training across SSA. The plan is to achieve this by 2020 [17].

The West African College of Surgeons (WACS) have developed their resident training and examination structure. Following 3-years of residency, trainees will be expected to have achieved qualification as Members of the College (MWACS), able to provide general ophthalmology services. Depending on the requirements of the country or region in which Members anticipate working, they may apply to undertake a further 2 years' subspecialist training to achieve Fellowship of the College (FWACS) [18].

District and mission hospitals are often used and accredited as training centres for post-graduate ophthalmology training [19]. These provide the volume of patients and the rural exposure to residents. 
Fig. 1 Flow diagram of literature search. PRISMA

flow diagram of literature search and selection process.

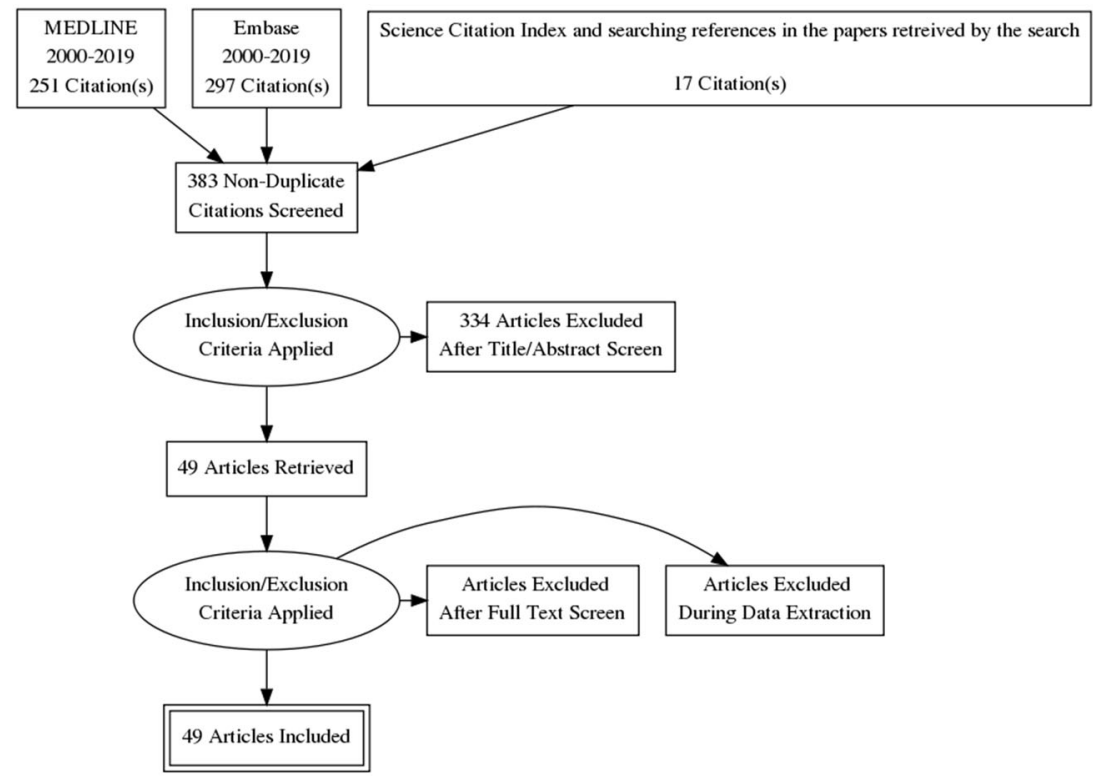

Table 7 NGO support of ophthalmology training in SSA.

\begin{tabular}{|c|c|c|}
\hline NGO & Countries supported & Website \\
\hline CBM $[106,107]$ & $\begin{array}{l}\text { Angola, Democratic Republic of Congo, Ethiopia, } \\
\text { Kenya, Rwanda, Malawi, South Africa, Swaziland, } \\
\text { Tanzania, Uganda, Zambia, Zimbabwe }\end{array}$ & www.cbm.org/ \\
\hline Cure Blindness [108] & Ghana, Ethiopia, Rwanda & www.cureblindness.org \\
\hline Fred Hollows Foundation & Rwanda & \\
\hline Fundacion Vision Mundi & Tanzania, Kenya, Burkina Faso & www.visionmundi.org \\
\hline Light for the World [109] & $\begin{array}{l}\text { Mozambique, Uganda, Democratic Republic of } \\
\text { Congo, Burkina Faso, Tanzania }\end{array}$ & www.light-for-the-world.org \\
\hline Lions International & Throughout SSA & www.lionsclubs.org/EN/how-we-serve/health/sight/ \\
\hline Ophthalmo Sans Frontieres [110] & Cameroon & www.opht-sans-frontieres.org \\
\hline Orbis [111] & $\begin{array}{l}\text { Cameroon, Ethiopia, Ghana, Kenya, Malawi, Nigeria, } \\
\text { Rwanda, South Africa, Tanzania, Uganda, Zambia }\end{array}$ & www.orbis.org/ \\
\hline $\begin{array}{l}\text { Organisation for the Prevention of } \\
\text { Blindness (OPC) [112] }\end{array}$ & $\begin{array}{l}\text { Benin, Burkina Faso, Cameroon, Central African } \\
\text { Republic, Chad, Guinea, Mali, Niger, Senegal }\end{array}$ & www.opc.asso.fr/ \\
\hline Seva Foundation [76] & Tanzania & www.seva.org/ \\
\hline Sightsavers $[74,113]$ & Guinea, Kenya, Mali, Tanzania, Uganda & www.sightsavers.org \\
\hline \multicolumn{3}{|l|}{$\begin{array}{l}\text { Tropical Health and Education } \\
\text { Trust (THET) }\end{array}$} \\
\hline World Sight Foundation [114] & South Africa & www.worldsightfoundation.com \\
\hline
\end{tabular}

Continuing medical education (CME) or continuous professional development (CPD) is provided by all Ophthalmology Colleges in SSA (Table 2). Colleges may jointly offer CME or CPD.

\section{Training the trainers}

The Royal College of Ophthalmologists and COECSA have been successful partners in a VISION 2020 LINK since 2008. The LINK has focused on the development of harmonised curricula for trainee ophthalmologists, training-the-trainers (TTT), fellowship examinations for graduating trainee ophthalmologists, online CME, research capacity building and a mentoring programme for young ophthalmologists [20]. The TTT programme has successfully developed a pyramid of trainers equipped to cascade knowledge, skills and teaching in training across COECSA [21]. 
Table 8 Total minimum prescribed surgical numbers over training.

\begin{tabular}{|c|c|c|c|c|c|c|}
\hline & $\begin{array}{l}\text { COECSA } \\
{[100]}\end{array}$ & $\begin{array}{l}\text { Ghana } \\
\text { [101] }\end{array}$ & $\begin{array}{l}\text { Malawi } \\
\text { [102] }\end{array}$ & $\begin{array}{l}\text { Tanzania } \\
{[103]}\end{array}$ & $\begin{array}{l}\text { South } \\
\text { Africa } \\
{[104]}\end{array}$ & $\begin{array}{l}\text { WACS } \\
{[105]}\end{array}$ \\
\hline Cataract extraction & $50-350$ & 50 & 200 & 150 & 300 & 100 \\
\hline Glaucoma surgery & & & 30 & 10 & 10 & 10 \\
\hline Lid surgery & & & 25 & 18 & 40 & 40 \\
\hline Strabismus & & & 20 & 3 & 20 & 3 \\
\hline Laser & & 40 & 50 & 53 & 60 & 10 \\
\hline Retinal detachment buckling & & & 10 & & $(20)$ & \\
\hline Conjunctival neoplasia excision & & & 25 & 5 & & \\
\hline Enucleation/evisceration & & 5 & 50 & 8 & 1 & 10 \\
\hline Exenteration & & & & 4 & & \\
\hline
\end{tabular}

COECSA College of Ophthalmologists of Eastern Central and Southern Africa, WACS West Africa College of Surgeons.

The ICO have developed 'milestones' and a teaching the teachers curriculum and initiative. Fondation Théa supports the ICO 'teaching the teachers' programme to improve training in ophthalmology in Francophone and Lusophone Africa [22, 23]. The ICO Programme Directors Course has been hosted at the Magrabi ICO Cameroon Eye Institute [24]. The Moorfields Eye Hospital partnership with WACS conducts a TTT course at the annual WACS meeting.

\section{Surgical education}

Surgical training in Francophone countries varies with the training programme, ranging from non-existent to full; while all Anglophone ophthalmology training programmes in SSA include surgical education [7].

\section{Specific prescribed/expected numbers}

Table 8 illustrates the total surgical numbers that trainees are expected to perform, by the completion of training (where published data is available).

\section{Simulation/dry-lab/wet-lab}

A full immersion computerised simulator for training in manual small incision cataract surgery is in development [25]. HelpMeSee support cataract surgery through surgical partners in Madagascar, Togo, The Gambia and Sierra Leone. The simulator and high-volume SICS training model is not currently being used in SSA [26].

One article highlighted that in Sudan, being a majority Islamic nation, pigs are not slaughtered there and hence no pig eyes are available. Goat eyes differ significantly from human eyes and hence have little value in wet lab teaching [27].
Ophthalmologists in Francophone countries will benefit from simulation surgical training at CHRU ClermontFerrand Gabriel-Montpied hospital in France [23].

\section{Sub-speciality residency training}

\section{Paediatric ophthalmology and strabismus}

Accessing training opportunities for paediatric ophthalmology and childhood cataract management is challenging, especially in Francophone Africa, and there continues to be a shortage of paediatric ophthalmologists and other staff members needed to staff child eye health tertiary facilities [28]. Paediatric ophthalmology resources are available in Francophone countries, and most are in the private sector. Surgical management of childhood cataract has become more specialised, and a team based approach has been adopted in the fellowship training of many paediatric ophthalmologists [29]. This includes improved anaesthetic services, and optometrist low-vision care. There has been a plea for the training of more ophthalmologists, and the equipping of more hospitals for strabismus surgery following an outcomes study in Cameroon [30]. Of a sample of 27 child eye health tertiary facilities across Africa, all ophthalmologists reported having undergone fellowship training in paediatric ophthalmology [31]. Two centres offer a paediatric ophthalmology fellowship which also provided training in paediatric ophthalmology for residents.

\section{Eye lids/oculoplastics/orbit}

Most surgical interventions for trachoma trichiasis are performed by non-physician technicians [32]. The surgical outcomes of these integrated eye care workers are the same as ophthalmologists [33]. Orbit and oculo-plastics training 
in Aravind has been supported by Foundation Théa for ophthalmologists from Benin [23].

\section{Cornea/anterior segment}

Surgical training, as well as service provision in terms of corneal grafts is a challenge as very few units in SSA have access to donated corneas for graft surgery.

\section{Cataract}

Not all ophthalmologist in SSA can necessarily be assumed to have been trained in cataract surgery [8]. All 54 training institutions teach cataract surgery to trainees. Surgical training opportunities in teaching and non-teaching hospitals are a challenge for many trainees where several compete for the few cataract cases booked for surgery. The use of mobile 'cataract' camps, cottage hospitals, and outreach clinics from bigger city hospitals has been advantageous in providing larger numbers of cataract cases for trainee ophthalmologists [34]. Improved training of surgeons was the top-ranked factor rated in a Delphi exercise for improving cataract surgical outcomes in Africa [35]. Some visiting faculty may teach cataract surgery, especially phacoemusification, however many training institutions do not routinely offer phacoemulsification training [36, 37].

Intra-operative complications of posterior capsule rupture have been reported at $6.2 \%$ for trainees in Nigeria [38]. Structured training and regular review of training curricula to reflect the need of the community was perceived by $92.6 \%$ of trainees to be an action that can increase CSR [39]. Trainees visit teaching institutions abroad. One Nigerian trainee reported on an 8-week cataract training course in Aravind Eye Hospitals, Madurai, India; having observed 1527 and performed (supervised) 75 extra-capsular cataract extractions [40]. Univariate analysis in a study in southern Ethiopia showed that higher cataract surgery productivity was associated with a higher number of surgeries during training [41].

\section{Glaucoma}

Glaucoma is very challenging to manage in SSA. There is an urgent need to address the widespread knowledge gap that currently exists among all levels of eye-care workers, including ophthalmologists, in secondary and tertiary healthcare institutions [42]. In a nationwide survey of 250 ophthalmologists in Nigeria, $79 \%$ felt their training in glaucoma was excellent or good. However, $46 \%$ felt they needed more training in glaucoma diagnosis and surgery [43]. In West Africa, the training of ophthalmologists has historically stressed cataract surgery, and put little emphasis on glaucoma [44]. Improved training in glaucoma as part of the eye care team is an important strategic component for improving glaucoma care services [45]. Advocacy, public awareness and training of glaucoma specialists were the three main recommendations for improving glaucoma care in Nigeria [46]. In Botswana, neither of the two general ophthalmologists had a sub-speciality interest in glaucoma [47].

Glaucoma surgical training is very challenging. Trabeculectomy is an intricate and long procedure to perform, patients' vision is slightly worse after surgery, in some areas $<50 \%$ of patients accept surgery, and in many areas of SSA the majority of ophthalmologists are reluctant to perform trabeculectomies [44, 48]. Surgical trabeculectomy is not commonly done in a teaching hospital $[49,50]$. Trainees have complained that they 'are really not doing any glaucoma surgery' [51].

It is recognised that to improve patient access to treatment for glaucoma, institutions need to be strengthened with training in surgical and laser skills, equipment, and the establishment of glaucoma care teams [52]. Glaucoma fellowship training is offered over 1 or 2 years at Aravind Eye Hospitals in India [53]. Glaucoma sub-speciality training for ophthalmologists from Ethiopia and Ghana has been provided by the Himalaya Cataract Project in Tilganga, Nepal [54]. Glaucoma sub-speciality training is offered in Cameroon [24].

\section{Retina}

There is good evidence of the need for training in the screening, diagnosis, and laser treatment of diabetic retinopathy in SSA [55]. A recent survey in Tanzania showed that only $9.5 \%$ of ophthalmologists had undergone specialist medical retina training [56]. Planning and developing diabetic retinopathy screening and management programmes requires a health systems approach, with multi-disciplinary teams led by ophthalmologists [57]. However, in SSA the number of ophthalmologists with specialist training in retinal diseases is low, hence there might be concern that self-identifying leaders will not emerge. The curriculum of the eye care workforce should reflect the demands of the diabetes epidemic [57].

During a long-term training collaboration between German and Kenyan teaching institutions and VR specialists, operations performed by local Kenyan ophthalmologists independently, without intervention of visiting German specialists, increased from $29.4 \%$ (in 2000) to $78.6 \%$ (in 2006) [58]. During the same period, the percentage of vitreo-retinal operations performed by resident surgeons alone increased from $55.6 \%$ (in 2000) to $85.9 \%$ (in 2007) [59].

A review of the surgical outcomes of 254 eyes in a training institution in East Africa showed good success rates of $73.2 \%$, and recommended that greater emphasis should 
be given to the recognition and treatment of retinal detachment in regional training programmes for ophthalmologists [60].

The establishment of fellowship training in, and facilities for pars plana vitrectomy in SSA, has been highlighted for not only retinal disease and vitreous opacities, but also the complications of cataract surgery [61]. The establishment of services increases the number of medical and surgical retinal cases for trainees to learn from [62].

\section{Neuro-ophthalmology}

There is only one published report of neuro-ophthalmology training in SSA, detailing a course that was developed for ophthalmologists in Malawi [63]. A survey in Nigeria showed that $47.7 \%$ of ophthalmologists had no formal training in neuro-ophthalmology during residency [64]. Sponsored sub-speciality training opportunities would serve to increase enrolment in neuro-ophthalmology.

\section{Community eye health}

In a cross-sectional survey of trainee ophthalmologists attending a community eye health $(\mathrm{CEH})$ course in Nigeria, $85 \%$ believed that the $\mathrm{CEH}$ programme was very relevant to Ophthalmology. However, $74 \%$ wanted the module duration reduced [65].

\section{Sub-speciality fellowship training}

Over two-thirds (69\%) of trainees in East Africa preferred to sub-specialise, favouring training institutions offering handson-training and proven experience in the sub-specialisation [66]. However, only a third (32\%) of practicing ophthalmologists had actually sub-specialised [67].

The Commonwealth Eye Health Consortium (CEHC), which includes COECSA and WACS as well as multiple institutions outside the region, has offered over one hundred clinical fellowship attachments to ophthalmologists from low and middle-income (LMIC) Commonwealth countries, most of which have come from SSA. The aim has been the enhancement of ophthalmology sub-specialty knowledge and skills, and the delivery of high-quality eye care, and subsequent return of Fellows to more effectively relieve the burden of blindness in their own countries [68].

The International Council of Ophthalmology (ICO) offers 3-12-month fellowship training opportunities to ophthalmology trainees from developing countries, including those in Africa [69]. These are funded in partnerships with Fred Hollows, the ICO Foundation and other sources.

COECSA and WACS have met to develop sub-specialist fellowship training in both sub-regions [70].
A five-layered 'Sandwich Fellowship' model has been developed in partnership between training institutions in Kenya and Canada [71]. The most widely used 'sandwich fellowship' in ophthalmology has been developed by the ICO. The ICO Sandwich Fellowships Programme is an addition to the ICO 3 months Fellowships Programme in which hosts visit the fellow's home clinic 1-2 years after completion of the fellow's first training stay. The aim of this visit is to find out where the fellow may need additional support. ICO fellows then return to the host hospital or clinic for a further 3 months' training to meet these individual needs. Another year later the Hosts visit again the fellow's institution to enhance ongoing cooperation [72].

The West African ophthalmic sub-speciality training centre has been established in Accra, Ghana. Part of the vision is to establish a programme of accredited subspecialist ophthalmology training within West Africa, and a faculty of West African trainers to teach [73].

Sightsavers, through the 'Promoting Quality Ophthalmology in East Africa' project have supported twelve ophthalmologists in sub-speciality training. Specialities included paediatric ophthalmology, glaucoma, oculoplastics, orbit, ocular oncology, phaco cataract surgery, community eye health, and epidemiology and biostatistics [74].

The Centre de Formation Ophtalmologique d'Afrique Centrale (CFOAC) provides sub-specialist training through a link with the University of Rostock [75]. Orbis has recently been a key partner in growing the Magrabi ICO Cameroon Eye Institute into a sub-speciality eye health training centre for Francophone Africa. The Seva Foundation supports sub-speciality training in corneal transplantation and retina [76].

\section{Exit examinations, qualifications, certification (local, national, regional and international)}

South African graduates of ophthalmology training programmes are required to pass the three-part Fellowship exams of the College of Ophthalmologists (which is within the Colleges of Medicine of South Africa) [77]. The COECSA Fellowship Exam is available to trainees who have completed their MMed Ophthalmology training and exams. Fellowship of WACS is an exit-level examination available to members. Figure 2 illustrates the different training infrastructures in terms of exit qualifications.

\section{External input from links, non-government organisations, and visiting faculty}

Ophthalmologists are supported in their training by many NGOs. Table 7 illustrates the numerous international 


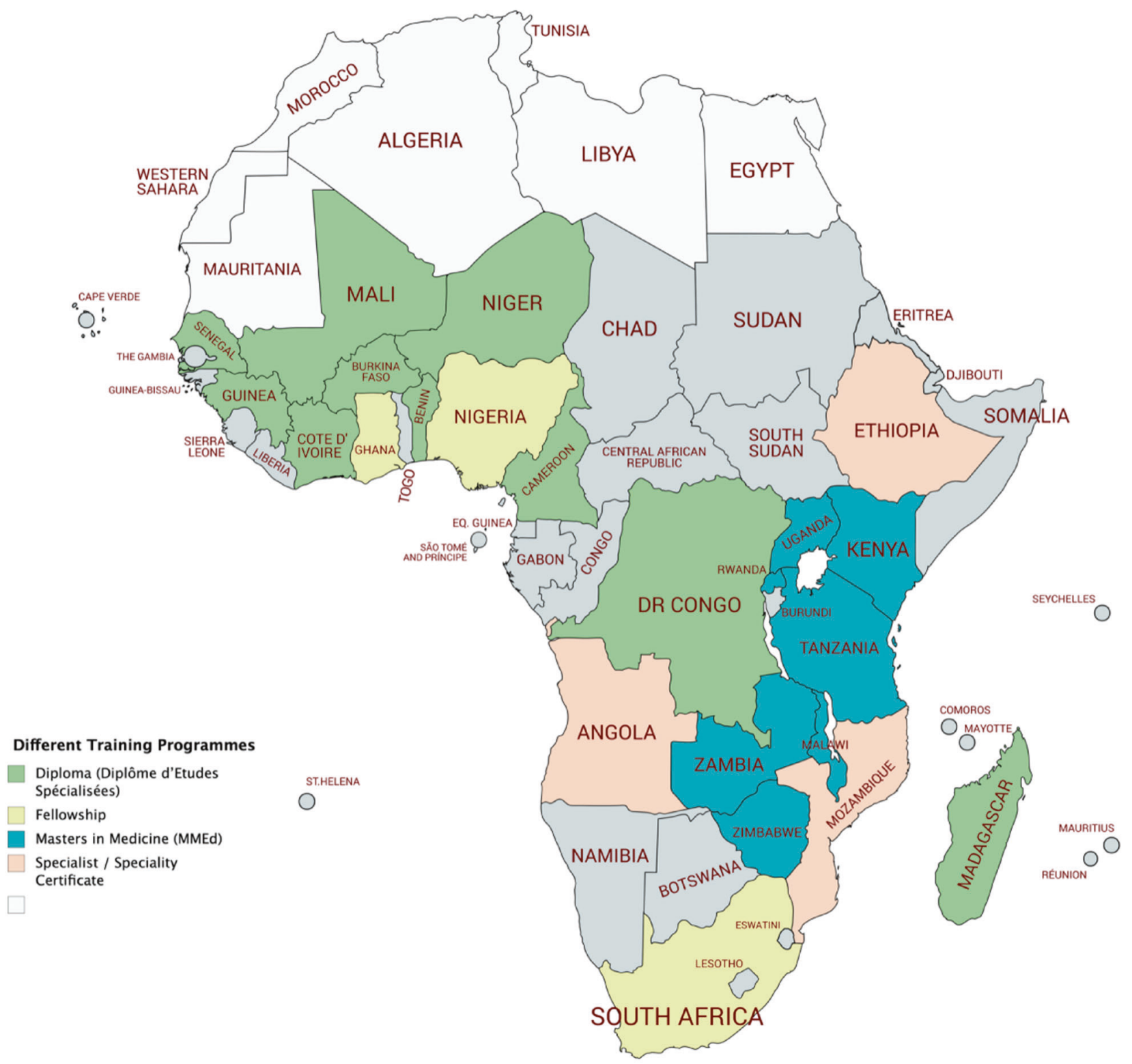

Fig. 2 Map of Africa illustrating training qualifications. A pictoral summary representation of the most common graduate ophthalmology training qualifications.

NGOs, and the countries in which they directly support (with either financial support of individual trainees, training institutions, or faculty) ophthalmology training.

A review article in Nigeria concluded that there is 'an abdication of responsibility for both training and service on the part of the government to the International NGOs. Teaching hospitals no longer generate enough patient surgical load to support training' [78].

Many ophthalmology training institutions have links with overseas institutions, in either Europe, the USA or elsewhere [79]. In many instances, these bilateral links and partnerships involve ophthalmology training. COECSA has linked with the Royal College of Ophthalmologists in the UK [20].

\section{Networks and collaboration}

Regional ophthalmology training initiatives and collaboration have been promoted in East Africa. The goal being to stimulate exchanges between training institutions, pooling educational resources, having joint teaching appointments, and promoting trainee mobility. It is recognised that there is a critical shortage of ophthalmologists in SSA, and this translates to an even greater shortage of ophthalmic trainers. Having a regional network of training institutions which are each supported to excel in their speciality areas of strength, would avoid the proliferation of poorly resourced 'comprehensive ophthalmology' training institutions in each country [80]. 
The Himalayan Cataract Project has partnered with Orbis International and the Moran Eye Centre (USA) to provide training opportunities for ophthalmologists in Ghana [81].

The 'Afro-German-Eye-Net' (AGENT) was established in 2006 and sub-speciality continuing medical education and Summer schools have been conducted in East and Central Africa [82].

The Diabetic Retinopathy Network was established in 2014. International participating ophthalmology institutions from nine countries in SSA are paired with UK VISION 2020 LINK ophthalmology departments are involved. The focus in East Africa has been on training centres and building up tertiary centres with an intended outcome of shared learning for the management of diabetic retinopathy [83].

The SAFO provides an important collaboration platform between ophthalmologists and national ophthalmology societies of Francophone countries in SSA. A main objective is to hold an annual congress, which in 2020 will be in Yaoundé, Cameroon with a focus on 'Training in Ophthalmology' ('Formation en ophtalmologie') [84].

\section{Attitudes, ethics and responsibilities}

A qualitative study in South Africa illustrated that the conventional practice in hospitals is for trainees to perform cataract surgery under supervision of consultants, and evaluation of the progress in ophthalmic surgical training was essentially an apprenticeship model [85]. Trainee ophthalmologists are required by their college to maintain a surgical logbook of procedures performed. This logbook contains some procedure details including complication rates, however no systematised quantitative evaluation of the logbook is conducted by trainees or the training institutions. In terms of improving cataract surgical outcomes in Africa, a Delphi exercise ranked improved training of surgeons' as the top priority [35].

\section{Audit}

Prospective monitoring has been shown to improve outcomes of cataract surgery, however it is unclear whether this is taught and re-enforced in ophthalmology training programmes [86].

The transfer of the desirable character, attitude, ethics and responsibilities, and indeed its assessment is a challenging aspect of training. There are no published examples where this has been addressed and documented.

\section{Broader training as part of the eye care team, research, and leadership}

COECSA has established the Young Ophthalmologists Forum for young and newly qualified ophthalmologists.
The networking forum helps participants to develop leadership and networking skills, as well as promote research [74].

The acquisition of surgical and managerial skills, as well as availability of qualitative ophthalmic resource material were judged to be adequate by $35(68.7 \%), 40(81.6 \%)$ and $38(74.5 \%)$ of trainees respectively in Nigeria [13].

A larger survey of Nigerian trainees showed that research was rated fourth in importance, after clinical service, teaching, and community service. Of the respondents, 91.8\% rated securing funding as either the 'higher' or the 'highest' among factors that negatively impacted conducting research [87]. More recently numerous SSA countries, including Kenya, Nigeria, and South Africa are making having a Ph.D. a prerequisite for senior career advancement in the university environment. There have been efforts to develop this capacity through the CEHC Ph.D. fellowship programme.

The Kilimanjaro Centre for Community Ophthalmology works to strengthen academic training of ophthalmology trainees through teaching and supervision of communitybased field work [88].

\section{Workforce}

Non-physician cataract surgeons (NPCS) are a valuable cadre in some countries in SSA. Successful eye care programmes using NPCS are characterised by having strong support, often by an ophthalmologist [89]. Medical officer cataract surgeons have high reported cataract surgical outputs, and more training for medical officer surgeons in South Africa has been recommended [90]. Training for Technicien Supérieur en Ophtalmologie is provided at the CFOAC in the Democratic Republic of Congo [75].

Reasons reported by African ophthalmologists for staying in their current region/country included good working conditions, commitment to help, the possibility of further training, family ties, and a general feeling of satisfaction [82]. Further reasons given by ophthalmology trainees in Ethiopia and Tanzania have similarly been wanting to support/serve community, family, and high demand of specialists [91]. The majority $(75 \%)$ of trainee ophthalmologists in Nigeria are unwilling to practice in rural areas, citing absence of infrastructure and facilities [92].

\section{Discussion}

Available published scientific data and evidence for ophthalmology training in SSA is sparse. The authors accept limitations within this review, including a rapidly changing landscape of information. It is also accepted that 'ophthalmology training' is a generic term, and that there are groups 
of professionals practicing ophthalmology, including NPCS and other allied healthcare professionals for whom training was not fully reported in this review. Ophthalmology training is one aspect of training in SSA, and a large experience is published relating to both medical and surgical training in other specialities from which many examples may be used to highlight potential avenues and approaches. This literature is absent from and outside of the scope of this review.

VISION 2020 recommended a target of 1 ophthalmologist per 250,000 population. Currently there are an estimated 2.5 ophthalmologists per million population in SSA, and an estimated 250-350 newly trained ophthalmologists per year. To attain the VISION 2020 recommended target of 4 ophthalmologists per million population, an increase of at least 1300 ophthalmologists would be needed in SSA. This solution, to train more ophthalmologists may seem obvious, however the situation is complex. Can current workforces absorb newly trained staff, not only in terms of work capacity; but also additional supervision, management and standard equipment? Are there policies and provisions for the deployment, remuneration, and retention of newly trained eye care professionals? [93]. As recognised by the IAPB and other key stakeholders, the training of new ophthalmologists is only the start. It is critical to be able to offer employment, equip them to be able to work, and ongoing support and continuing training opportunities.

Sub-speciality surgical education is challenging in SSA. There is a lack of corneal graft donor tissue. Vitreo-retinal surgery is highly dependent on expensive equipment. Surgical management of glaucoma has been recommended as the first-line treatment, however there is evidence that ophthalmologists in SSA do not perform enough glaucoma surgery [44, 94, 95]. A study in Nigeria showed that the number of glaucoma surgeries performed per ophthalmologist per month was 0.5 and 1.1 for tertiary and secondary hospitals respectively [50]. Reasons suggested for reluctance to offer glaucoma surgery included late presentation, lack of patient satisfaction, complications of surgery, and negative publicity [51]. This low number of surgical procedures for glaucoma impacts on training and surgical opportunities for ophthalmology trainees in SSA. Major strides have been recently made in harmonisation of subspeciality training and curricula in SSA.

A survey of ophthalmologists at CME courses in East Africa illustrated that the main reasons for staying in their current region/country were good working conditions, commitment to help, possibility of further training, familial ties and general feeling of satisfaction. Professional development elsewhere and better income abroad were named as the main reasons for considering migration [82].

A comparative study of OST in Malawi and Germany highlighted that overall goal of training in Germany is mainly a medical ophthalmologist, whereas in Malawi it is an ophthalmic surgeon [96].

Networks and partnerships are ubiquitous for training in ophthalmology in SSA. National or university ophthalmology training institutions partner with other eye units to provide training opportunities in-country. Six main colleges of ophthalmology encompass the West Africa and COECSA subregions, and Southern Africa; representing a total of 49 countries. Further international links exist with the IAPB, ICEH, ICO, the Royal College of Ophthalmologists, and other colleges and societies. National, sub-regional and international partnerships exist between numerous universities, Ministries of Health, NGOs, eye care institutions and individuals. These networks, collaborations and partnerships appear fundamental to the sustainable training of ophthalmologists to the highest standards maximising often limited resources.

\section{Conclusions}

Appropriately qualified ophthalmologists and allied eye health care professionals should be available and skilled, well-supported and productive if the goals of VISION 2020 are to be reached. Targets for $\mathrm{HReH}$ are useful for planning, monitoring, and resource mobilisation; however, they need to be updated and informed by evidence of effectiveness and efficiency [7].

Training of ophthalmologists is a complex and multifaceted task (Fig. 3). There are challenges in appropriate selection, capacity, and funding of available training institutions. Numerous learning outcomes demand curriculum, time, faculty, support, and appropriate assessment. Aside from the remaining backlog of cataract blindness and visual impairment, there is a drive, although perhaps not always evidence-based, for further sub-specialisation in the region [97-99]. In most SSA countries, tertiary level institutions are more developed than secondary level facilities. Strengthening these secondary-level facilities would increase access to eye care beyond capital cities. While subspecialists are key for training and education in tertiary level institutions, secondary level facilities require ophthalmologists skilled in comprehensive ophthalmology, including cataract and glaucoma surgery as well as laser procedures.

Ultimately there is a huge burden of eye disease in SSA. There are limited resources in the region: not only in terms of eye-care service provision, but in the number of training institutions for ophthalmologists (and indeed all eye healthcare workers), the number of available trainer faculty, and trainers' time. What is evident is the successful and innovative approach in the SSA region to deal with this challenge. The national, regional and international 
Fig. 3 Ophthalmology

training. Interaction overview diagram illustrating the complexity and multi-faceted nature of training in ophthalmology.

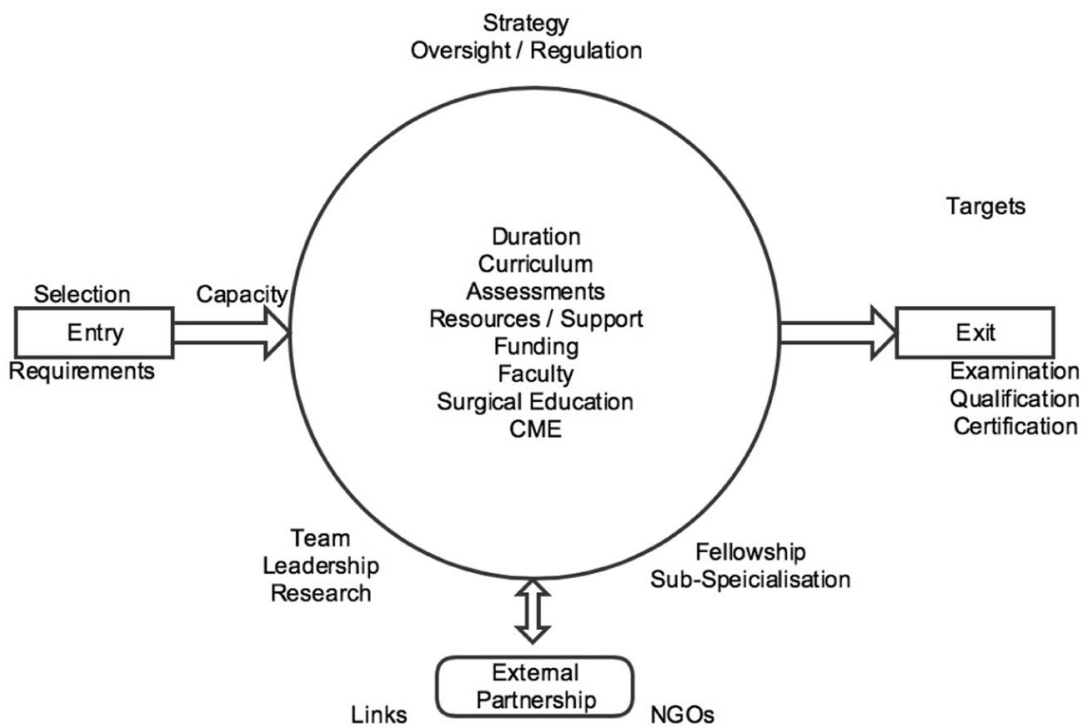

collaborations; sharing of expert resources; and standardisation of training curricula are lessons that many parts of the world could benefit from.

New, innovative and collaborative methods of teaching and learning are needed in response to what the demands on the doctor will be in the future, due to the many and rapid technological changes. Training needs to be in alignment with the demands on tomorrow's doctor in terms of sustainability, the environment, profit and people.

\section{Summary}

- Training in ophthalmology is complex and multifaceted.

- Standardised and competency-based ophthalmology curricula have developed.

- There is a regional drive for sub-specialisation within ophthalmology.

- Networks, collaborations and partnerships are important to the sustainable training of ophthalmologists to the highest standards, maximising often limited resources.

Funding WD is funded by the British Council for the Prevention of Blindness, the Ulverscroft Foundation and CBM. MJB is supported by the Wellcome Trust (207472/Z/17/Z).

\section{Compliance with ethical standards}

Conflict of interest The authors declare that they have no conflict of interest.

Publisher's note Springer Nature remains neutral with regard to jurisdictional claims in published maps and institutional affiliations.

\section{References}

1. WorldBank. Sub-Saharan Africa. 2015. http://data.worldbank. org/region/sub-saharan-africa. Accessed 13 April 2017.

2. Flaxman SR, Bourne RRA, Resnikoff S, et al. Global causes of blindness and distance vision impairment 1990-2020: a systematic review and meta-analysis. Lancet Glob Health. 2017;5: e1221-34. https://doi.org/10.1016/S2214-109X(17)30393-5.

3. Bourne RRA, Flaxman SR, Braithwaite T, et al. Magnitude, temporal trends, and projections of the global prevalence of blindness and distance and near vision impairment: a systematic review and meta-analysis. Lancet Glob Health. 2017;5:e888-97. https://doi.org/10.1016/S2214-109X(17)30293-0.

4. Khairallah M, Kahloun R, Bourne R, et al. Number of people blind or visually impaired by cataract worldwide and in world regions, 1990 to 2010. Investig Ophthalmol Vis Sci. 2015;56: 6762-9. https://doi.org/10.1167/iovs.15-17201.

5. Naidoo K, Gichuhi S, Basanez MG, et al. Prevalence and causes of vision loss in sub-Saharan Africa: 1990-2010. Br J Ophthalmol. 2014;98:612-8. https://doi.org/10.1136/bjophthalmol-2013304081.

6. Resnikoff S, Lansingh VC, Washburn L, et al. Estimated number of ophthalmologists worldwide (International Council of Ophthalmology update): will we meet the needs? $\mathrm{Br} \mathrm{J}$ Ophthalmol. 2019. https://doi.org/10.1136/bjophthalmol-2019-314336.

7. Courtright $\mathrm{P}$, Mathenge $\mathrm{W}$, Kello $\mathrm{AB}$, et al. Setting targets for human resources for eye health in sub-Saharan Africa: what evidence should be used? Hum Resour Health. 2016;14:11. https://doi.org/10.1186/s12960-016-0107-x.

8. Palmer JJ, Chinanayi F, Gilbert A, et al. Trends and implications for achieving VISION 2020 human resources for eye health targets in 16 countries of sub-Saharan Africa by the year 2020 . Hum Resour Health. 2014;12:45. https://doi.org/10.1186/14784491-12-45.

9. Palmer JJ, Chinanayi F, Gilbert A, et al. Mapping human resources for eye health in 21 countries of sub-Saharan Africa: current progress towards VISION 2020. Hum Resour Health. 2014;12:44. https://doi.org/10.1186/1478-4491-12-44.

10. IAPB. Training Institutions Database IAPB Africa. 2015. https://ia pblive.blob.core.windows.net/resources/1d5f5f5218244b8e9b4563 726858d105.pdf? width $=150$ \&height $=150$. Accessed 13 Feb 2017. 
11. Pizzarello L, Abiose A, Ffytche T, et al. VISION 2020: the right to sight: a global initiative to eliminate avoidable blindness. Arch Ophthalmol. 2004;122:615-20. https://doi.org/10.1001/archopht. 122.4.615

12. Bode CO, Olatosi JO, Ademuyiwa A. Accreditation of training programmes by the West African College of Surgeons. J West Afr Coll Surg. 2012;2:95-109.

13. Ayanniyi AA, Adeboye A, Ademola-Popoola DS. Ophthalmology training in Nigeria: the trainee ophthalmologists' perspective. Niger Postgrad Med J. 2007;14:94-8.

14. Adeboye A, Ayanniyi AA, Ademola-Popoola DS, et al. The choice of ophthalmology as a career among Nigerian medical interns. Afr J Med Med Sci. 2006;35:321-3.

15. Masanganise R, Samkange C, Mukona D, et al. Competency based ophthalmology training curriculum for undergraduate medical students in Zimbabwe. Cent Afr J Med. 2015;61:44-8.

16. IAPB. Orbis secures $\$ 2$ million funding from the David and Molly Pyott Foundation to strengthen eye health in Zambia. 2019. https://www.iapb.org/news/orbis-secures-usd-2-millionfunding-from-the-david-and-molly-pyott-foundation-tostrengthen-eye-health-in-zambia/.

17. ICO. Historic Meeting Sets Groundwork for Standardized Training in Sub-Saharan Africa. 2016. http://www.icoph.org/ news/news_detail/330/Historic-Meeting-Sets-Groundwork-forStandardized-Training-in-Sub-Saharan-Africa.html. Accessed 20 Apr 2017.

18. Day S. The COECSA/WACS sub-specialist fellowship development workshop. 2018. https://www.iapb.org/news/the-coecsa-wa cs-sub-specialist-fellowship-development-workshop/.

19. Ezegwui IR, Ajewole J. Monitoring cataract surgical outcome in a Nigerian mission hospital. Int Ophthalmol. 2009;29:7-9. https://doi.org/10.1007/s10792-007-9182-2.

20. Mwangi N, Zondervan M, Bascaran C. Analysis of an international collaboration for capacity building of human resources for eye care: case study of the college-college VISION 2020 LINK. Hum Resour Health. 2017;15:22. https://doi.org/10.1186/ s12960-017-0196-1.

21. Corbett MC, Mathenge W, Zondervan M, et al. Cascading training the trainers in ophthalmology across Eastern, Central and Southern Africa. Glob Health. 2017;13:46. https://doi.org/ 10.1186/s12992-017-0269-x.

22. Thea. Access to training: promoting high quality medical training. 2019. https://www.laboratoires-thea.com/en/fondationthea/access-training.

23. Théa. L'accès à la formation. 2020. https://www.laboratoires-thea. com/fr/fondation/lacces-la-formation. Accessed 28 July 2020.

24. El-Maghraby A, elMaghraby A, Alireza M, et al. Magrabi ICO Cameroon Eye Institute, Yaounde, Cameroon: ophthalmology subspecialty patient care and training center in Central Africa. Am J Ophthalmol. 2019;197:98-104. https://doi.org/10.1016/j. ajo.2018.09.010.

25. Singh A, Strauss GH. High-fidelity cataract surgery simulation and third world blindness. Surg Innov. 2015;22:189-93. https://doi.org/10.1177/1553350614537120.

26. HelpMeSee. 2015 Annual Report. 2016. http://report.helpmesee. org/ar2015?utm_source=Website\&utm_medium =Link\&utm_ca mpaign=2015_report. Accessed 19 Apr 2017.

27. Dnyanmote S. My experience of teaching phacosurgery on visalis 100 in Sudan and Nigeria. Rom J Ophthalmol. 2015; 59:107-11.

28. Bronsard A, Geneau R, Duke R, et al. Cataract in children in subSaharan Africa: an overview. Expert Rev Ophthalmol. 2018;13: 343-50. https://doi.org/10.1080/17469899.2018.1555037.

29. Courtright P. Childhood cataract in sub-Saharan. Afr Saudi j. 2012;26:3-6. https://doi.org/10.1016/j.sjopt.2011.10.006.
30. Mvogo CE, Bella AL, Ellong A, et al. Surgical management of primary exotropia in Cameroon. Clin. 2007;1:471-4.

31. Agarwal PK, Bowman R, Courtright P. Child eye health tertiary facilities in Africa. J AAPOS. 2010;14:263-6. https://doi.org/10. 1016/j.jaapos.2010.02.007.

32. Burton M, Habtamu E, Ho D, et al. Interventions for trachoma trichiasis. Cochrane Database Syst Rev. 2015:CD004008. https://doi.org/10.1002/14651858.CD004008.pub3.

33. Alemayehu W, Melese M, Bejiga A, et al. Surgery for trichiasis by ophthalmologists versus integrated eye care workers: a randomized trial. Ophthalmology. 2004;111:578-84. https://doi.org/ 10.1016/j.ophtha.2003.06.030.

34. Bekibele C. A comparative evaluation of outcome of cataract surgery at Ago-Iwoye, Ogun State. Niger J Surg Res. 2004;6:1-2.

35. Buchan JC, Dean WH, Foster A, et al. What are the priorities for improving cataract surgical outcomes in Africa? Results of a Delphi exercise. Int Ophthalmol. 2018;38:1409-14. https://doi. org/10.1007/s10792-017-0599-y.

36. Forzano O, Andre JM, Conrath J, et al. Teaching phacosection in a tropical setting. J Fr Ophtalmol. 2004;27:913-7.

37. Gogate PM. Small incision cataract surgery: complications and mini-review. Indian J Ophthalmol. 2009;57:45-9.

38. Ezegwui I, Aghaji A, Okpala N, et al. Evaluation of complications of extracapsular cataract extraction performed by trainees. Ann Med Health Sci Res. 2014;4:115-7. https://doi.org/10.4103/ 2141-9248.126616.

39. Ayanniyi AA, Adepoju FG, Owoeye JF. Trainee ophthalmologists' opinions on ways to improve cataract surgical rate. Ann Afr Med. 2009;8:276-80. https://doi.org/10.4103/1596-3519.59585.

40. Aghaji AE, Natchiar G. Structured extracapsular cataract extraction-intraocular lens microsurgical training: Report of a trainee's experience. Niger J Clin Pract. 2011;14:70-3. https://doi.org/10.4103/1119-3077.79262.

41. Habtamu E, Eshete Z, Burton MJ. Cataract surgery in Southern Ethiopia: distribution, rates and determinants of service provision. BMC Health Serv Res. 2013;13:480. https://doi.org/10. 1186/1472-6963-13-480.

42. Standefer MD. Challenges in glaucoma management in developing countries-is vision 2020 ready for glaucoma? Niger J Ophthalmol. 2010;18:1-2.

43. Kyari F, Nolan W, Gilbert C. Ophthalmologists' practice patterns and challenges in achieving optimal management for glaucoma in Nigeria: results from a nationwide survey. BMJ Open. 2016;6: e012230. https://doi.org/10.1136/bmjopen-2016-012230.

44. Egbert PR. Glaucoma in West Africa: a neglected problem. Br J Ophthalmol. 2002;86:131-2.

45. Kyari F, Gilbert C, Blanchet K, et al. Improving services for glaucoma care in Nigeria: implications for policy and programmes to achieve universal health coverage. Br J Ophthalmol. 2017;101:543-7. https://doi.org/10.1136/bjophthalmol-2016310040 .

46. Onwubiko SN, Udeh NN, Nkwegu O, Ukwu DO, Nwachukwu NZ. Glaucoma care in Nigeria: is the current practice poised to tackle this emerging sight-threatening disease? Int Ophthalmol. 2019;39:2385-90. https://doi.org/10.1007/s10792-019-01078-9.

47. Razai MS, Jackson DJ, Falama R, et al. The capacity of eye care services for patients with glaucoma in Botswana. Ophthalmic Epidemiol. 2015;22:403-8. https://doi.org/10.3109/09286586. 2015.1010689.

48. Quigley HA, Buhrmann RR, West SK, et al. Long term results of glaucoma surgery among participants in an east African population survey. Br J Ophthalmol. 2000;84:860-4.

49. Adegbehingbe B, Majemgbasan T. A review of trabeculectomies at a Nigerian teaching hospital. Ghana Med J. 2007;41:176-80. 
50. Adekoya BJ, Onakoya AO, Shah SP, et al. Surgical output and clinic burden of glaucoma in lagos, Nigeria. J Glaucoma. 2014;23:41-5. https://doi.org/10.1097/IJG.0b013e318264cd80.

51. Adekoya BJ, Adepoju FG, Mashood KF, et al. Challenges in the management of glaucoma in a developing country; a qualitative study of providers' perspectives. Niger J Med. 2015;24:315-22.

52. Kyari F, Gilbert C, Blanchet K, et al. Improving services for glaucoma care in Nigeria: implications for policy and programmes to achieve universal health coverage. Br J Ophthalmol. 2017;15:15. https://doi.org/10.1136/bjophthalmol-2016-310040.

53. IAPB. Magnitude of glaucoma the rationale for glaucoma training 2017. https://www.iapb.org/news/magnitude-of-glaucoma-the-ra tionale-for-glaucoma-training/. Accessed 1 Sep 2019.

54. IAPB. Sub specialty training is key to addressing glaucoma. 2019. https://www.iapb.org/news/sub-specialty-training-is-keyto-addressing-glaucoma/.

55. Glover SJ, Allain TJ, Cohen DB. Diabetic retinopathy in an urban diabetic clinic in Malawi. Am J Trop Med Hyg. 2009;1:93.

56. Mafwiri M, Mwakyusa N, Shilio B, Sanyiwa A. Situational analysis of infrastructure and human resources for diabetic retinopathy services in Tanzania. J Ophthalmol East Cent South Afr. 2015;18:49-58.

57. Poore S, Foster A, Zondervan M, et al. Planning and developing services for diabetic retinopathy in Sub-Saharan Africa. Int $\mathbf{J}$ Health Policy Manag. 2015;4:19-28. https://doi.org/10.15171/ ijhpm.2015.04.

58. Schonfeld CL, Kollmann M, Nyaga P, et al. Training program for vitreoretinal surgery in Nairobi, Kenya from 2000-2006]. Klin Monatsbl Augenheilkd. 2008;225:857-62. https://doi.org/ 10.1055/s-2008-1027602.

59. Schonfeld CL, Kollmann M, Nyaga P, et al. New approach in training in East Africa: vitreo-retinal surgery from 2000 to 2007 in Kenya. Br J Ophthalmol. 2010;94:1402. https://doi.org/10. 1136/bjo.2009.163865.

60. Yorston DB, Wood ML, Gilbert C. Retinal detachment in East Africa. Ophthalmology. 2002;109:2279-83.

61. Oluleye TS. Should posterior vitrectomy be made a priority in ophthalmic facilities of sub Saharan Africa. Open J Ophthalmol. $2013 ; 7: 1-3$

62. Oluleye TS. Is age-related macular degeneration a problem in Ibadan, Sub-Saharan Africa?. Clin Ophthalmol. 2012;6:561-4. https://doi.org/10.2147/OPTH.S27470.

63. Schulze Schwering M, Kayange P, Wilhelm H. Neuroophthalmology in Malawi. J Neuroophthalmol. 2013;33:e11-2. https://doi.org/10.1097/WNO.0b013e318290fc29.

64. Ogun OA. Encouraging subspecialty practice by constructively in uencing trainees early in their careers will improve advocacy for neuro-ophthalmology among Nigerian ophthalmologists. J Med Educ Curric Dev. 2016;3:149-55.

65. Ayanniyi AA. Community eye health module in West Africa: the trainee ophthalmologists perspectives. West Afr J Med. 2009; 28:245-8.

66. Kariuki M, Kithuka P, Irunga D. Sub-specialization preferences among ophthalmology masters students in Eastern Africa. J Ophthalmol East Cent South Afr. 2014;18:3-7.

67. Kariuki M, Kithuka P, Irunga D, Koome G. Status of subspecialization among practicing ophthalmologists from Eastern Africa. J Ophthalmol East Cent South Afr. 2015;19:14-8.

68. CEHC. Clinical fellowships programme. 2017. http://cehc.lshtm. ac.uk/clinical-fellows/. Accessed 18 Apr 2017.

69. ICO. ICO Fellowships Program. 2017. http://www.icoph.org/ refocusing_education/fellowships.html. Accessed 18 Apr 2017.

70. IAPB. The COECSA-WACS sub-specialist fellowship development workshop. 2018. https://www.iapb.org/news/the-coecsa-wacs-subspecialist-fellowship-development-workshop/.
71. Kassam F, Damji KF, Kiage D, et al. The Sandwich fellowship: a subspecialty training model for the developing world. Acad Med. 2009;84:1152-60. https://doi.org/10.1097/ACM.0b013e3181acf95c.

72. ICO. ICO fellowships 2001-2016: a 15-year success story. 2016. http://www.icoph.org/downloads/15YearsICOFellowships.pdf.

73. The West African Ophthalmic Sub-Specialty Training Centre: Consensus Meeting Report. 2012. http://www.vision2020uk.org. uk/download/archive_1/docs/Consensus_summary_2012_ FINAL.doc. Accessed 21 Apr 2017.

74. Sightsavers. End of term evaluation of the promoting quality ophthalmology in East Africa project. 2014. https://www.sightsa vers.org/wp-content/uploads/2015/09/20003_EACO_ Promoting_Quality_Ophthamology_2014_Final_Evaluation_ Report.pdf. Accessed 19 Apr 2017.

75. CFOAC. Centre de Formation Ophtalmologique d'Afrique Centrale. https://cfoac.cd/. 2020. Accessed 25 Aug 2020.

76. Seva. Our priorities-training. 2017. http://www.seva.org/site/Pa geServer?pagename=programs/training. Accessed 18 Apr 2017.

77. CMSA. Structure and fees for the fellowship of the College of Ophthalmologists of South Africa. 2017. https://www.cmsa.co. za/view_exam.aspx?examid=28. Accessed 18 Apr 2017.

78. Babalola $\mathrm{OE}$. The peculiar challenges of blindness prevention in Nigeria: a review article. Afr J Med Med Sci. 2011;40:309-19.

79. Zondervan M, Walker C, Astbury N. The VISION 2020 LINKS program: building capacity for eye care internationally. Eye News. 2013;19:34-9.

80. Mathenge W. A call to pool our regional resources through conversation, collaboration and collective action. J Ophthalmol East Cent South Afr. 2013;17:1-2.

81. CureBlindness. Contributions at work in Ghana. 2016. https://www.cureblindness.org/work/where-we-work/Ghana.

82. Nentwich MM, Schaller UC, Klauss V. Reasons reported by African ophthalmologists for staying in Africa and for considering migrating. Int Ophthalmol. 2014;34:887-92. https://doi. org/10.1007/s10792-014-9896-x.

83. Astbury N, Burgess P, Foster A, et al. Tackling diabetic retinopathy globally through the VISION 2020 LINKS diabetic retinopathy network. Eye News. 2017;23:30-4.

84. SAFO. Société Africaine Francophone d'Ophtalmologie. 2020. http://safo-info.org/. Accessed 28 July 2020.

85. Haastrup OO, Buchan JC, Cassels-Brown A, et al. Are we monitoring the quality of cataract surgery services? A qualitative situation analysis of attitudes and practices in a large city in South Africa. Middle East Afr J Ophthalmol. 2015;22:220-5. https://doi.org/10.4103/0974-9233.151878.

86. Yorston D, Gichuhi S, Wood M, et al. Does prospective monitoring improve cataract surgery outcomes in Africa? $\mathrm{Br} \mathrm{J}$ Ophthalmol. 2002;86:543-7.

87. Mahmoud AO, Ayanniyi AA, Lawal A, et al. Survey of the attitudes of nigerian ophthalmologists to and resources for ophthalmic research. Middle East Afr J Ophthalmol. 2012;19:123-8. https://doi.org/10.4103/0974-9233.92128.

88. KCCO. What we do. 2019. http://www.kcco.net/what-we-do/.

89. Hale I, Lewallen S, Courtright P. Task-shifting: ophthalmologist to non-physician cataract surgeon: a review of the evidence. Moshi, Tanzania: Kilimanjaro Centre for Community Ophthalmology (KCCO); 2013.

90. Lecuona K, Cook C. South Africa's cataract surgery rates: why are we not meeting our targets? S Afr Med J. 2011;101:510-2.

91. Knoll KM, Philippin H, Makupa W, et al. Emigration-an option for African resident physicians? opinions from Tanzania and Ethiopia. Ophthalmologe. 2019;116:357-63. https://doi.org/10. 1007/s00347-018-0690-4.

92. Achigbu E, Okoye O, Aghaji A, et al. Rural eye care practicesurvey of ophthalmology resident doctors in Nigeria. Int Eye Sci. 
2018;18:1370-3. https://doi.org/10.3980/j.issn.1672-5123.2018. 8.03 .

93. Blanchet K, Gilbert C, de Savigny D. Rethinking eye health systems to achieve universal coverage: the role of research. Br J Ophthalmol. 2014;98:1325-8. https://doi.org/10.1136/bjophtha lmol-2013-303905.

94. Bowman RJ, Kirupananthan S. How to manage a patient with glaucoma in Africa. Community Eye Health. 2006;19:38-9.

95. Cook C. Chronic glaucoma case finding and treatment in rural Africa: some questions and answers. Community Eye Health. 2001;14:43-4.

96. Schulze Schwering M, Batumba HN. [Resident training in ophthalmology: can the German system learn from the Malawian one?]. Klin Monatsbl Augenheilkd. 2013;230:72-5. https://doi. org/10.1055/s-0032-1312782.

97. Kariuki M, Kithuka $P$, Irunga $D$, et al. Status of subspecialisation among practicing ophthalmologists in Eastern Africa. J Ophthalmol East Cent South Afr. 2015;19:14-8.

98. Kariuki M, Kithuka P, Irunga D. Sub-specialisation preferences among ophthalmology masters students in Eastern Africa. J Ophthalmol East Cent South Afr. 2014;18:3-7.

99. Kayange P. Sub-specialization; is it the way to go? J Ophthalmol East Cent South Afr. 2014;18:1-2.

100. COECSA. COECSA curriculum: surgical skills (SS) study guide. 2017. http://curriculum.coecsa.org/course/view.php?id= 83. Accessed 19 Apr 2017.

101. GCPS. Membership in ophthalmology. 2011. http://gcps.edu. gh/wp-content/uploads/2014/07/Opthalmology-MembershipCurriculum-2011.pdf. Accessed 19 Apr 2017.

102. Schulze Schwering M, Spitzer MS, Kalua K, et al. Training ophthalmologists for developing economies: an African-German partnership. Postgrad Med J. 2014;90:61-2. https://doi.org/10. 1136/postgradmedj-2013-132059.

103. KCMUCo. Prospectus 2016-2018. 2016. http://kcmuco.ac.tz/wpcontent/uploads/2016/11/kcmuco-prospectus.pdf. Accessed 19 Apr 2017.

104. CMSA. Fellowship of the college of ophthalmologists of South Africa: FC Ophth(SA) Regulations. 2017. https://www.cmsa.co. za/view_exam.aspx?examid=28. Accessed 19 Apr 2017.

105. WACS. Training curriculum for the membership and fellowship programme. 2014. http://www.wacscoac.org/downloads/ OPHTHALMOLOGYCURRICULUM.pdf. Accessed 19 Apr 2017.

106. CBM. West African ophthalmology training programme. 2011. http://www.cbm.org/West-African-ophthalmology-trainingprogramme-304377.php. Accessed 18 Apr 2017.

107. CBM. CBM worldwide-Africa. 2017. http://www.cbm.org/ Africa-252070.php. Accessed 18 Apr 2017.

108. CureBlindness. Work-where we work. 2017. http://www. cureblindness.org/. Accessed 18 Apr 2017.

109. LFTW. Where we work. 2017. https://www.light-for-the-world. org/. Accessed 18 Apr 2017.

110. OSF. Organisation. 2017. http://www.opht-sans-frontieres.org/ organisationa.html. Accessed 18 Apr 2017.

111. Orbis. Training, research, advocacy. 2017. https://orbisafrica.co. za/training/. Accessed 18 Apr 2017.

112. OPC. Programmes. 2017. http://www.opc.asso.fr/?-Programmes\&lang=fr. Accessed 18 Apr 2017.

113. Sightsavers. What we do-sight. 2017. https://www.sightsavers. org/what-we-do/sight/. Accessed 18 Apr 2017.

114. WSF. Africa-Rwanda. 2017. http://www.worldsightfoundation. com/project-headline-02/. Accessed 18 Apr 2017. 